\section{OPEN ACCESS}

Edited by:

Kenneth Michael Pollard,

The Scripps Research Institute,

United States

Reviewed by:

lan P. Giles,

University College London,

United Kingdom

Marvin Fritzler,

University of Calgary, Canada

${ }^{*}$ Correspondence:

Christine G. Parks

parks1@mail.nih.gov

Specialty section:

This article was submitted to Autoimmune and Autoinflammatory

Disorders,

a section of the journa

Frontiers in Immunology

Received: 29 March 2019 Accepted: 13 June 2019

Published: 11 July 2019

Citation:

Parks CG, Santos AdSE, Lerro CC, DellaValle CT, Ward MH, Alavanja MC,

Berndt SI, Beane Freeman LE,

Sandler DP and Hofmann JN (2019) Lifetime Pesticide Use and Antinuclear Antibodies in Male Farmers From the Agricultural Health Study.

Front. Immunol. 10:1476

doi: 10.3389/fimmu.2019.01476

\title{
Lifetime Pesticide Use and Antinuclear Antibodies in Male Farmers From the Agricultural Health Study
}

\begin{abstract}
Christine G. Parks ${ }^{1 *}$, Aline de Souza Espindola Santos ${ }^{2}$, Catherine C. Lerro ${ }^{3}$, Curt T. DellaValle ${ }^{4}$, Mary H. Ward ${ }^{3}$, Michael C. Alavanja ${ }^{3}$, Sonja I. Berndt ${ }^{3}$, Laura E. Beane Freeman ${ }^{3}$, Dale P. Sandler ${ }^{1}$ and Jonathan N. Hofmann ${ }^{3}$
\end{abstract}

${ }^{1}$ Epidemiology Branch, National Institute of Environmental Health Sciences, Research Triangle Park, Durham, NC, United States, ${ }^{2}$ Institute in Collective Health Studies, Federal University of Rio de Janeiro, Rio de Janeiro, Brazil, ${ }^{3}$ Occupational and Environmental Epidemiology Branch, Division of Cancer Epidemiology and Genetics, National Cancer Institute, Bethesda, MD, United States, ${ }^{4}$ All of Us Research Program, Office of the Director, National Institutes of Health, Bethesda, MD, United States

Farming and pesticide use have been associated with systemic autoimmune diseases, and while certain organochlorine insecticides and other pesticides are suspected to influence risk, the role of specific pesticides in the development of systemic autoimmunity is not known. We measured serum antinuclear autoantibodies (ANA) by immunofluorescence on Hep-2 cells in 668 male farmers in the study of Biomarkers of Exposure and Effect in Agriculture (BEEA; 2010-2013), an Agricultural Health Study (AHS) subcohort. We examined ANA in relation to lifetime use of 46 pesticides first reported at AHS enrollment (1993-1997) and updated at intervals through BEEA enrollment. Odds ratios (OR) and 95\% confidence intervals (Cl) were estimated after adjusting for age, state, education, season of blood draw, current pesticide use, and correlated pesticides. Having ANA antibodies (3 or 4+ intensity at a 1:80 dilution, 21\% of study participants) was associated with a reported history of seeking medical care due to exposure to pesticides (OR 2.15; 95\% Cl 1.17, 3.95), use of the fumigant methyl bromide (OR 3.16; 95\% $\mathrm{Cl} 1.05,9.5)$, and use of petroleum oil/distillates (OR 1.50; $95 \% \mathrm{Cl} 1.00,2.25$ ). Using a higher threshold (3 or $4+$ at a 1:160 dilution, 9\%) ANA positivity was associated with the carbamate insecticide aldicarb (OR 4.82; 95\% Cl 1.33, 17.5) and greater combined use of four cyclodiene organochlorine insecticides (top tertile of intensity-weighted lifetime days vs. no use; OR т3 3.20; 95\% $\mathrm{Cl} 1.10,9.27$ ). By contrast, greater use of non-cyclodiene organochlorine insecticides was inversely associated with ANA (1:80 dilution 3 or $4+$, OR тз $0.24 ; 95 \% \mathrm{Cl} 0.08,0.72$ ). Specific autoantibodies (to extractable nuclear antigens and anti-dsDNA), measured on those with ANA detected at the 1:80 dilution 3 or $4+$, were seen in 15 individuals (2\%), and were associated with use of two or more cyclodiene organochlorine insecticides and several other pesticides (e.g., carbofuran, ethylene dibromide). These findings suggest that specific pesticide exposures may have long-term effects on ANA prevalence and support the hypothesis that certain organochlorine insecticides may increase the risk of developing systemic autoimmunity.

Keywords: epidemiology-analytic (risk factors), autoantibodies, pesticides, occupational epidemiology, cohort study (or longitudinal study) 


\section{INTRODUCTION}

Farming occupation and pesticide use have been associated with elevated risk of systemic autoimmune diseases (1-9), but the role of specific pesticide exposures in the development of systemic autoimmunity is not known. Systemic autoimmunity, as measured by anti-nuclear antibodies (ANA; based on an intensity of $3+$ or $4+$ at the 1:80 titer), is estimated to occur in 12 to $16 \%$ of the US population ages 12 and older, with higher rates in women and older adults (10). Overall ANA positivity, including lower levels of ANA (i.e., at the 1:40 titer), is even more common, seen in almost a third of healthy adults (11). By contrast, higher level ANA (i.e., 1:160 titer and higher) are considered more likely to be clinically relevant; elevated ANA are typically present in patients with systemic lupus erythematosus, an uncommon autoimmune disease, and ANA prevalence is often elevated in family members and patients with other systemic autoimmune diseases $(12,13)$.

Various pesticides have immunotoxic effects and case series have suggested associations with autoantibodies (14). Only a few epidemiologic studies have examined ANA in relation to specific agricultural pesticides. In a cross-sectional study of Canadian farmers, ANA prevalence was significantly higher in association with use of some, but not all organochlorine insecticides (15). In another similar study from the same region, both positive and inverse associations were seen for ANA with the recent use of different herbicides and fungicides, though estimates were imprecise due to small sample size (16). Other studies have examined serum levels of organochlorine pesticides in relation to ANA, with inconsistent findings (17-19).

In the current study, we examined associations of lifetime pesticide use with ANA in a sample of male farmers from the Biomarkers of Exposure and Effect in Agriculture (BEEA) study in the Agricultural Health Study (AHS) (20), a large prospective cohort that includes farmers in Iowa and North Carolina (21). Cross-sectional studies show that ANA prevalence rises slowly with age over several decades $(10,22,23)$. In theory, the loss of immune tolerance enabling the production of antibodies to self-antigens may occur at any time in the past, thereby conferring life-long potential to produce ANA. Therefore, our analyses focused on the association of ANA with lifetime exposures to pesticides, with a specific focus on the organochlorine insecticides.

\section{METHODS}

\section{Study Population and Sample}

The design and methodology for enrollment and specimen collection in the AHS and BEEA study have been described $(20,21)$. BEEA participants were recruited from among the male private pesticide applicators in the AHS who were $\geq 50$ years of age, resided in Iowa or North Carolina, had completed the AHS enrollment questionnaire as well as two follow-up interviews (in 1999-2003 and 2005-2010), and had never been diagnosed with cancer (other than non-melanoma skin cancer). In the current investigation, we assessed ANA and other markers of autoimmunity in 699 participants enrolled in BEEA between June 2010 and September 2013. Because a diagnosis of autoimmune disease might have influenced pesticide use or reporting, we excluded 31 individuals who reported a doctor diagnosis of systemic autoimmune disease at AHS enrollment, for a final analysis sample of 668 participants. The study was approved by Institutional Review Boards at the National Cancer Institute and other participating institutions, and all participants provided written informed consent.

\section{Questionnaire Data}

Lifetime history of 50 specific pesticides was assessed based on participant report at AHS enrollment in 1993-1997. Pesticide use was updated in two follow-up surveys in 1999-2003 and 20052010, and at BEEA enrollment. All participants completed these four questionnaires, and $62 \%(N=410)$ also completed a "takehome" questionnaire at AHS enrollment that solicited additional detailed information on the use of 28 of the pesticides, including organochlorine insecticides. The enrollment questionnaire also ascertained information about days per year and years of use pesticides overall, along with mixing and application practices, use of protective equipment, and repairing equipment. Data were updated in the follow-up surveys and used to derive intensity-weighted lifetime days of use (24). In the enrollment questionnaire, participants were also asked whether they had ever sought medical care or been hospitalized due to pesticide exposure, and in the take home questionnaire they were asked about high pesticide exposure events (HPEE) and whether they ever had ever been diagnosed with pesticide poisoning (25). Data on HPEE, medical treatment and pesticide poisoning were updated in follow-up surveys and combined as a single variable with three levels: (1) any medical treatment due to pesticides or pesticide poisoning diagnosis, (2) HPEE without medical treatment, and (3) neither. A health history, including diagnosis with rheumatoid arthritis and systemic lupus erythematosus, was collected at enrollment and throughout follow-up. BEEA enrollment questionnaires also collected data on current medication use, which were used to identify use of disease modifying antirheumatic drugs (DMARDs) and non-steroidal anti-inflammatory drugs. Questionnaires are available at https:// aghealth.nih.gov/collaboration/questionnaires.html; the primary DMARD medications reported included methotrexate and hydroxychloroquine, as well as leflunomide, sulfasalazine, azathioprine, mycophenolate mofetil, cyclosporine, and biologics, but not steroids.

\section{Assays}

Non-fasting blood specimens were collected in the participant's home and transported and shipped cold via overnight delivery before processing, aliquoting, and storage at $-80^{\circ} \mathrm{C}$. Antinuclear antibodies (ANA) were measured by the gold standard immunofluorescence assay for serum samples under a standardized protocol in a clinical rheumatology laboratory with prior experience with high-throughput testing in epidemiologic studies (26); in brief, ANA were detected using HEp-2 cell slides (Kallestad, Bio-Rad Laboratories, Hercules, CA), incubated with a 1:80 dilution of sera, then washed and incubated with the burro anti-human polyvalent immunoglobulin FITC conjugate (Kallestad) read using fluorescent microscopy (Leitz 
Fluorescence Scope, 50/1.0 magnification). Samples with a positive ANA ( 3 or $4+$ at the 1:80 dilution) were subsequently tested for extractable nuclear autoantibodies (ENA), including RNP, SM, SSA (combined 52 and $60 \mathrm{kDa}$ ) and SSB (QUANTA Lite, Inova Diagnostics, San Diego, CA; RNP/SM/SSBochterlony; SSA-ELISA) and anti-dsDNA antibodies (EIA, Kallenstad). Anti-citrullinated peptide (anti-CCP) antibodies, specific for rheumatoid arthritis (27), were measured by secondgeneration ELISA; any detectable anti-CCP were seen in $2.3 \%$ of the study sample and $<1 \%$ were positive based on a clinical cut-point of $25 \mathrm{AU} / \mathrm{ml}$, within the expected prevalence in the general population (27). Testing for anti-TPO antibodies was previously described, with antibodies seen in $9 \%$ of the study sample (28). Coefficients of variation were $<10 \%$ for all assays. Frequencies are shown in Supplemental Table 1.

\section{Analyses}

Three cut-points for ANA positivity were considered: first, ANA prevalence was based on a rating of $3+$ or $4+$ at 1:80 dilution, similar to recently published population-level data on ANA (10). We then lowered the cut-point, by including lower-level ANA, i.e., those with a rating of $2+$ at 1:80 dilution, similar to a positive reading at the 1:40 dilution used in prior studies. Finally, we raised the cut-point in analyses limited to those with higher titer ANA based on having $3+$ or $4+$ intensity rating at the 1:160 dilution. Only five individuals had a positive reading $(3+)$ at the 1:320 level (one with anti-dsDNA antibodies), so these were not considered separately. These groups are labeled as "Any" $(\geq 1: 802+)$, "Moderate-higher" $(\geq 1: 803+)$ and Higher $(\geq 1: 160$ $3+)$, to indicate the increasing threshold for positivity. Three sets of models were run comparing the different definitions of ANA positives to those with no detectable ANA, using logistic regression to calculate odds ratios (OR) and 95\% confidence intervals (CIs), adjusting for age and other covariates at BEEA enrollment (i.e., BMI, state, education, season of blood draw, and use of agricultural pesticides in the past 12 months). We considered a $p$-value of $<0.05$ to be statistically significant, and a value of 0.05 to $<0.10$ as suggestive. Associations were estimated for lifetime use of pesticides (overall, and for use of 46 specific pesticides with at least five ANA positive participants exposed). We also adjusted for correlated pesticides (Spearman's rho $\geq 0.40$ in the sample, Supplemental Table 2) when confounding was observed, i.e., inclusion in the model changed the effect estimate by at least $10 \%$.

We explored intensity-weighted lifetime days for individual organochlorine insecticides (Supplemental Table 3), but numbers were smaller due to a lack of data on those who did not complete the take-home questionnaire, and we saw no clear exposure-response patterns. To increase statistical power, we also grouped the OCs into two groups based on similarities in structure and function. We then tested the hypothesis that ANA was related to use of certain organochlorine insecticides, examining exposure-response relationships across cumulative intensity-weighted lifetime days for two groups of insecticides, summing the intensity-weighted lifetime days for each individual pesticide in the group: cyclodienes (aldrin, dieldrin, chlordane, and heptachlor) and other organochlorines (DDT, toxaphene, and lindane). These two groups were correlated ( $r h o=0.53$ for any use), so they were run in a mutually adjusted model. Finally, we explored the frequency of disease-specific autoantibodies (i.e., ENA and anti-dsDNA autoantibodies) by pesticide use, including combined organochlorine variables (e.g., none, 1, or 2 or more cyclodienes used), and estimated age-adjusted ORs to describe these associations. Sensitivity analyses excluded potential incident cases of autoimmune disease, i.e., based on self-reported rheumatoid arthritis or other autoimmune disease, DMARD use, or the presence of anti-thyroid or anti-citrullinated peptide autoantibodies identified during AHS follow-up or at BEEA enrollment.

\section{RESULTS}

Of 668 samples tested, 282 (42\%) had detectable ANA: 143 (21\%) had any detectable ANA (i.e., $\geq 1: 80$ dilution at $2+$ intensity reading), 139 (21\%) had ANA detected at $\geq 1: 803$ or $4+$ and $60(9 \%)$ had ANA detectable at $1: 1603$ or $4+$. Sample characteristics by ANA status are shown in Table 1. Participants with ANA were older: those over age 60 years had two to three times the odds of having moderate to higher-levels of ANA (at $\geq 1: 803$ or $4+$ ) compared with those ages 5055 years. After adjusting for age, no associations were noted for smoking status, BMI, state, current farming status and season at the time of blood draw. During follow-up or at BEEA enrollment, 44 participants reported an incident diagnosis of an autoimmune disease, which was associated with overall ANA (OR 3.62; 95\%CI 1.87, 6.98) (Supplemental Table 1). Among those with moderate to high level ANA, 15 (2\% of the total sample) had disease-specific autoantibodies, i.e., ENA $(n=6)$ or anti-dsDNA $(n=11)$.

Neither lifetime years nor average days per year of any pesticide use at AHS enrollment was associated with ANA positivity (Table 2). However, having sought medical care due to pesticide exposure was associated with having moderate to high level ANA (OR 2.15; 95\%CI 1.17, 3.95). In analyses of specific pesticides (Table 3), we saw suggestive associations of high ANA with lifetime use of the organochlorine insecticide heptachlor (OR 1.93; 95\%CI 0.96, 3.90) and the organophosphate insecticide diazinon (OR 1.64; 95\%CI 0.92, 2.92), and a significant association with the carbamate insecticide aldicarb (OR 4.82; 95\%CI 1.33, 17.5). Moderate to high level ANA were associated with the fumigant methyl bromide (OR 3.16; $95 \% \mathrm{CI} 1.05$ to 9.50 ), and suggestively associated with use of petroleum oil/distillates as an herbicide (OR 1.50; 95\%CI $1.00,2.25$ ). By contrast, overall ANA (low, moderate, or high) were inversely associated with the organophosphate insecticides fonofos (OR 0.72; 95\%CI 0.50, 1.00) and malathion (OR 0.62; $95 \% \mathrm{CI} 0.42,0.91$ ), and the herbicide butylate (OR 0.72; 95\%CI $0.52,0.99)$.

We examined the relationship of ANA with intensityweighted lifetime days of use for organochlorines grouped as cyclodienes (heptachlor, chlordane, aldrin, and dieldrin) and non-cyclodienes (DDT, lindane, toxaphene), in a mutually adjusted model (Table 4). Prevalence of high ANA was associated 
TABLE 1 | Participant characteristics and age-adjusted associations with ANA.

\begin{tabular}{|c|c|c|c|c|c|c|c|}
\hline \multirow{3}{*}{ Characteristics $^{3}$} & \multicolumn{4}{|c|}{ ANA Level ${ }^{1}$} & \multicolumn{3}{|c|}{ Age-adjusted OR $(95 \% \mathrm{Cl})^{2}$} \\
\hline & $\begin{array}{l}\text { Negative } \\
N=386\end{array}$ & $\begin{array}{l}1: 802+ \\
N=143\end{array}$ & $\begin{array}{c}1: 803 / 4+ \\
N=79\end{array}$ & $\begin{array}{c}1: 1603 / 4+ \\
N=60\end{array}$ & $\begin{array}{l}\text { Any ANA } \\
(\geq 1: 802+) \\
\text { vs. none }\end{array}$ & $\begin{array}{c}\text { Moderate-higher } \\
\text { ANA }(\geq 1: 803 / 4+) \\
\text { vs. none }\end{array}$ & $\begin{array}{l}\text { Higher ANA } \\
\text { ( } \geq 1: 1603 / 4+) \\
\text { vs. none }\end{array}$ \\
\hline & \multicolumn{4}{|c|}{$N(\%)$} & & & \\
\hline \multicolumn{8}{|l|}{ Age (years) } \\
\hline $50-55$ & $84(22)$ & $24(17)$ & $12(15)$ & $7(12)$ & Referent & Referent & Referent \\
\hline $56-60$ & $102(26)$ & $34(24)$ & $14(18)$ & $5(8)$ & $1.02(0.62,1.67)$ & $0.82(0.41,1.66)$ & $0.59(0.18,1.92)$ \\
\hline $61-70$ & $107(28)$ & $39(27)$ & $28(35)$ & $24(40)$ & $1.66(1.05,2.64)$ & $2.15(1.18,3.91)$ & $2.69(1.11,6.55)$ \\
\hline $70+$ & $93(24)$ & $46(32)$ & $25(32)$ & $24(40)$ & $2.00(1.25,3.18)$ & $2.33(1.27,4.27)$ & $3.10(1.27,7.56)$ \\
\hline \multicolumn{8}{|l|}{ Smoked } \\
\hline Past & $120(31)$ & $53(37)$ & $30(38)$ & $36(60)$ & $1.21(0.86,1.70)$ & $1.15(0.76,1.77)$ & $1.06(0.59,1.92)$ \\
\hline Current & $14(4)$ & $8(6)$ & $4(5)$ & $3(5)$ & $1.74(0.82,3.67)$ & $1.73(0.68,4.45)$ & NA \\
\hline \multicolumn{8}{|l|}{ BMI } \\
\hline Overweight & $166(43)$ & $74(52)$ & $38(48)$ & $24(42)$ & $1.38(0.89,2.16)$ & $1.47(0.82,2.64)$ & $1.06(0.49,2.32)$ \\
\hline Obese & $150(39)$ & $44(31)$ & $32(41)$ & $25(42)$ & $1.17(0.74,1.86)$ & $1.58(0.87,2.87)$ & $1.32(0.60,2.89)$ \\
\hline $\begin{array}{l}\text { Used agricultural } \\
\text { pesticides, past year }\end{array}$ & $288(75)$ & $100(70)$ & $54(68)$ & $39(65)$ & $0.90(0.63,1.30)$ & $0.91(0.58,1.44)$ & $0.92(0.49,1.71)$ \\
\hline Spring/summer ${ }^{4}$ & $206(53)$ & $76(53)$ & $39(49)$ & $37(62)$ & $1.03(0.75,1.40)$ & $1.07(0.72,1.58)$ & $1.44(0.82,2.54)$ \\
\hline State (NC) & $54(14)$ & $18(13)$ & $11(14)$ & $9(15)$ & $0.93(0.57,1.34)$ & $0.88(0.55,1.55)$ & $0.88(0.40,1.93)$ \\
\hline
\end{tabular}

NC, North Carolina; NA, not applicable due to fewer than five exposed cases.

${ }^{1}$ ANA Level shows four exclusive categories of ANA positivity based on highest reading observed; Negative, none detected at 1:80 dilution.

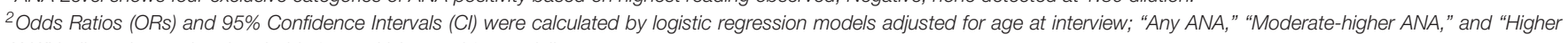
ANA" indicate increasing thresholds for positivity used for modeling.

${ }^{3}$ All were current at BEEA enrollment, except for state at AHS study enrollment.

${ }^{4}$ Blood collected in spring or summer, compared to fall or winter.

with being in the top tertile of intensity-weighted lifetime days of combined cyclodiene use vs. no use $\left(\mathrm{OR}_{\mathrm{T} 3} 3.20\right.$; $95 \%$ CI 1.10, 9.27). By contrast, greater use of non-cyclodiene organochlorines was inversely associated with moderate to high ANA $\left(\mathrm{OR}_{\mathrm{T} 3} 0.24 ; 95 \% \mathrm{CI} 0.08,0.72\right)$, which was similar to the association with greater DDT use (OR 0.35; 95\%CI $0.13,0.99$, above the median intensity-weighted lifetime days; Supplemental Table 3).

In age adjusted models, having specific ENA or anti-dsDNA autoantibodies was associated with using two or more cyclodiene organochlorine insecticides, and with fonofos, cyanazine, and ethylene dibromide (Table 5). Because these comparisons are based on only a small number of participants with ENA or anti-dsDNA autoantibodies, confidence limits were wide, and we did not adjust these models for other covariates or correlated pesticides. All but one of the participants with diseasespecific autoantibodies used carbofuran $(p=0.002)$. We also saw suggestive associations of disease-specific autoantibodies with aldicarb and methyl bromide, and an inverse association with malathion. Sensitivity analyses showed no substantial impact of excluding participants with a potential autoimmune disease during follow-up or at BEEA enrollment, i.e., who reported an incident diagnosis of an autoimmune disease since enrollment, or used disease-specific antirheumatic drugs, or were positive for thyroid or anti-CCP autoantibodies (not shown).

\section{DISCUSSION}

Our findings provide evidence that moderate to higher level ANA are associated with past use of specific pesticides and a history of seeking medical care for pesticide exposures in male farmers. Further, our results support the hypothesis that certain types of organochlorine insecticides may increase risk of developing autoimmunity. Two other pesticides, the carbamate insecticide aldicarb, and fumigant methyl bromide, were associated with increased odds of having moderate or higher-level ANA. By contrast, two of more commonly used organophosphate insecticides (in this sample), malathion and fonofos, and the herbicide butylate, were related to lower overall ANA. Together, these results suggest complex and lasting effects of some pesticides on autoimmunity.

Systemic autoimmune diseases are more common in reproductive age women, so past studies have been interested in the potential endocrine-disrupting effects of organochlorine pesticides on autoimmunity. Experimental and epidemiologic studies suggest a nuanced relationship. For example, the insecticide chlordecone (a cyclodiene) accelerated in a dose-dependent fashion the development of disease-specific anti-dsDNA autoantibodies in ovariectomized female mice in the NZB X NZW(F1) model of lupus (29). However, these effects did not appear to be mediated by estrogen-related mechanisms and did not extend to DDT. A recent study of a U.S. population 
TABLE 2 | ANA associations with lifetime pesticide use and high pesticide exposure events.

\begin{tabular}{|c|c|c|c|c|c|c|c|}
\hline \multirow{3}{*}{ Overall pesticide use } & \multicolumn{4}{|c|}{ ANA Level ${ }^{1}$} & \multicolumn{3}{|c|}{ Adjusted OR $(95 \% \mathrm{Cl})^{2}$} \\
\hline & $\begin{array}{l}\text { Negative } \\
N=386\end{array}$ & $\begin{array}{c}1: 802+ \\
N=143\end{array}$ & $\begin{array}{c}1: 803 / 4+ \\
N=79\end{array}$ & $\begin{array}{c}1: 1603 / 4+ \\
N=60\end{array}$ & $\begin{array}{l}\text { Any ANA } \\
(\geq 1: 802+) \\
\text { vs. none }\end{array}$ & $\begin{array}{c}\text { Moderate-higher } \\
(\geq 1: 803 / 4+) \text { ANA } \\
\text { vs. none }\end{array}$ & $\begin{array}{l}\text { Higher ANA } \\
(\geq 1: 803 / 4+) \\
\text { vs. none }\end{array}$ \\
\hline & \multicolumn{4}{|c|}{$N(\%)$} & & & \\
\hline \multicolumn{8}{|c|}{ MIXED OR APPLIED PESTICIDES - ENROLLMENT } \\
\hline \multicolumn{8}{|l|}{ Years } \\
\hline$\leq 10$ & $65(18)$ & $22(16)$ & $12(16)$ & $9(15)$ & Referent & Referent & Referent \\
\hline $11-20$ & $128(35)$ & $53(38)$ & $21(27)$ & $16(27)$ & $1.07(0.66,1.73)$ & $0.88(0.47,1.65)$ & $0.92(0.38,2.23)$ \\
\hline $21-30$ & $130(35)$ & $47(33)$ & $33(43)$ & $26(43)$ & $1.04(0.64,1.69)$ & $1.11(0.61,2.03)$ & $1.11(0.48,2.58)$ \\
\hline $30+$ & $47(13)$ & $19(14)$ & $11(14)$ & $9(15)$ & $0.78(0.41,1.55)$ & $0.68(0.31,1.53)$ & $0.60(0.20,1.81)$ \\
\hline \multicolumn{8}{|l|}{ Average days/year } \\
\hline$<10$ & $155(42)$ & $56(40)$ & $33(43)$ & $31(53)$ & Referent & Referent & Referent \\
\hline $10-19$ & $125(34)$ & $49(35)$ & $11(14)$ & $13(15)$ & $0.90(0.62,1.31)$ & $0.70(0.43,1.14)$ & $0.52(0.26,1.05)$ \\
\hline $20+$ & $89(24)$ & $36(25)$ & $18(23)$ & $15(25)$ & $1.07(0.71,1.60)$ & $0.95(0.57,1.57)$ & $0.91(0.45,1.81)$ \\
\hline \multicolumn{8}{|c|}{ HIGH EXPOSURE EVENTS/MEDICAL CARE/POISONING ${ }^{3}$} \\
\hline Yes, but did not seek care & $47(12)$ & $24(17)$ & $11(14)$ & $6(10)$ & $1.37(0.86,2.18)$ & $1.22(0.66,2.25)$ & $0.94(0.37,2.35)$ \\
\hline Sought medical care & $29(8)$ & $9(6)$ & $15(18)$ & $7(12)$ & $1.47(0.85,2.52)$ & $2.15(1.17,3.95)$ & $1.41(0.58,3.46)$ \\
\hline
\end{tabular}

sample $(N=4,340$; National Health and Examination Survey, 1999-2004) reported no significant associations of measured organochlorines with moderate or higher ANA $(3+$ or $4+$ at the 1:80 titer) after adjusting for multiple comparisons (17); in men, however, ANA was negatively associated with the DDT metabolite, DDE, and oxychlordane (a chlordane metabolite) at the $p<0.05$ level. By contrast, in a small sample of African-American male farmers, higher DDE levels were suggestively (but non-significantly) associated with ANA (1:40 titer, equivalent to "overall" in the current study) (19). This later sample was selected from the population of rural eastern North Carolina as an add-on study to the AHS (non-overlapping with the current study sample); participants had an average of 2.2 (SD 5.5) years of DDT use and 12.3 (SD 13.4) years of overall pesticide use. In the current study sample, prevalence of high or moderate ANA was associated with greater intensity-weighted lifetime days using any of the four cyclodiene organochlorine insecticides (i.e., aldrin, dieldrin, chlordane, and heptachlor), and inversely associated with greater use of the non-cyclodiene organochlorine insecticides (especially DDT). Notably, DDT and the cyclodiene insecticides are no longer in use in the U.S., but our results suggest persistent effects on immunity decades later.

Our analyzing cyclodienes separately from the other organochlorines had both empirical and theoretical rationale. In analyses of ever-use of the individual organochlorine insecticides, we saw suggestive positive associations with heptachlor and chlordane, but not with DDT. This was consistent with results by Rosenberg et al. who reported that
ANA prevalence was associated with lifetime organochlorine use, excluding DDT and methoxychlor in a sample of 322 rural adults (15). Organochlorine insecticides share a chlorinated hydrocarbon structure and physical properties such as lipid solubility and environmental persistence. Their toxic effects on insects are due to hyperexcitation of nerve cells. The DDT-type chemicals work by perturbing sodium gates, while the cyclodiene insecticides impact the $\gamma$-aminobutyric acid (GABA) receptor, impairing chlorine influx (30). While GABA is best known as a neurotransmitter, emerging evidence suggests an important role in immune function and innate immunity $(31,32)$. The closely related cyclodienes, chlordane, and heptachlor, have been associated with ANA in case series (33). Similar studies of aldrin and its breakdown product, dieldrin, were not identified in the autoimmunity literature, but there is some evidence of immunosuppressive effects of aldrin/dieldrin across different studies (34-36). In our data, having used two or more of these pesticides was also associated with having any of the disease-specific autoantibodies (e.g., anti-dsDNA autoantibodies). Together, these findings suggest these pesticides may increase the risk of developing clinically relevant autoimmunity. Lindane, a cyclohexane, also impacts GABA receptor function, but we saw limited evidence of an association with ANA. Besides their neurotoxicity, organochlorine pesticides can have other effects, for example endocrine disruption through estrogen or pregnane $\mathrm{X}$ receptors $(37,38)$, so targeted research is needed to identify which pathways may impact autoimmunity. 
TABLE 3 | Antinuclear antibodies and lifetime use of insecticides.

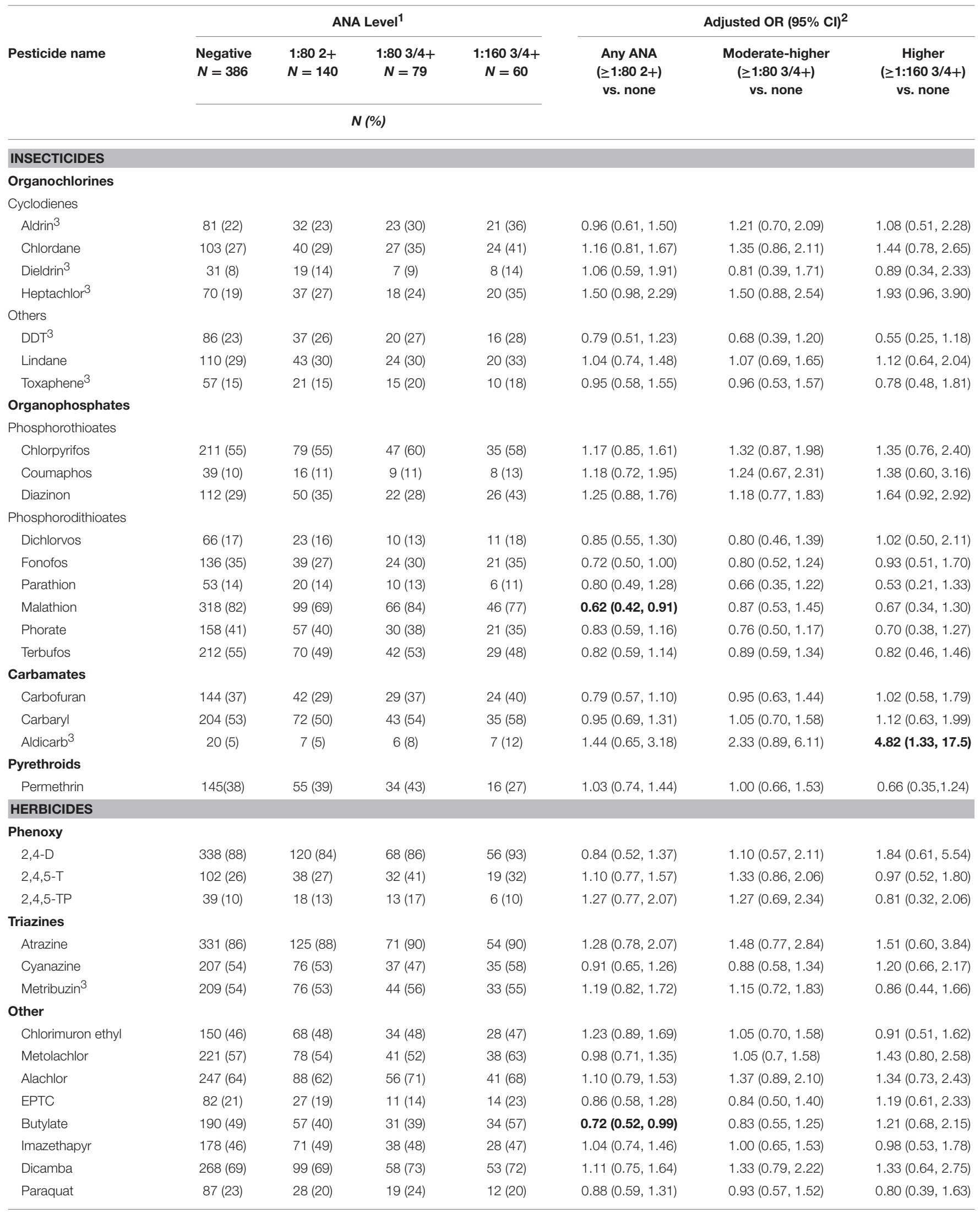


TABLE 3 | Continued

\begin{tabular}{|c|c|c|c|c|c|c|c|}
\hline \multirow{2}{*}{ Pesticide name } & \multicolumn{4}{|c|}{ ANA Level ${ }^{1}$} & \multicolumn{3}{|c|}{ Adjusted OR $(95 \% \mathrm{Cl})^{2}$} \\
\hline & \multicolumn{4}{|c|}{$N(\%)$} & $\begin{array}{l}\text { Any ANA } \\
(\geq 1: 802+) \\
\text { vs. none }\end{array}$ & $\begin{array}{c}\text { Moderate-higher } \\
(\geq 1: 803 / 4+) \\
\text { vs. none }\end{array}$ & $\begin{array}{l}\text { Higher } \\
(\geq 1: 1603 / 4+) \\
\text { vs. none }\end{array}$ \\
\hline Glyphosate & $353(92)$ & $129(90)$ & $73(92)$ & $54(90)$ & $0.99(0.57,1.73)$ & $1.08(0.53,2.21)$ & $0.88(0.34,2.26)$ \\
\hline Pendimethalin & $193(50)$ & $70(49)$ & $44(56)$ & $29(48)$ & $1.02(0.75,1.41)$ & $1.11(0.74,1.66)$ & $0.92(0.43,1.62)$ \\
\hline Petroleum Oil/Distillates & $204(53)$ & $83(58)$ & $50(63)$ & $38(63)$ & $1.34(0.97,1.84)$ & $1.50(1.00,2.25)$ & $1.48(0.83,2.62)$ \\
\hline \multicolumn{8}{|c|}{ FUNGICIDES AND FUMIGANTS } \\
\hline Ethylene dibromide ${ }^{3}$ & $13(3)$ & $8(6)$ & $3(4)$ & $3(5)$ & $2.06(0.84,5.08)$ & $1.93(0.61,6.10)$ & NA \\
\hline Maneb/Mancozeb³ & $25(6)$ & $11(8)$ & $6(7)$ & $2(3)$ & $0.85(0.40,1.79)$ & $0.50(0.18,1.40)$ & NA \\
\hline Methyl bromide ${ }^{3}$ & $25(6)$ & $9(6)$ & $8(10)$ & $7(12)$ & $1.94(0.82,4.60)$ & $3.16(1.05,9.50)$ & $3.61(0.79,16.6)$ \\
\hline Metalaxyl ${ }^{3}$ & $74(19)$ & $25(18)$ & $16(20)$ & $12(20)$ & $0.92(0.59,1.44)$ & $0.94(0.54,1.64)$ & $0.94(0.43,2.05)$ \\
\hline
\end{tabular}

NA, not applicable due to fewer than five ANA positive individuals who were exposed.

${ }^{1}$ ANA Level shows four exclusive categories of ANA positivity based on highest reading observed.

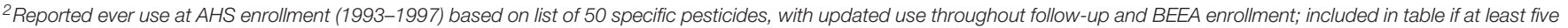
ANA positive individuals exposed to individual pesticides.

${ }^{3}$ Odds Ratios (ORs) and 95\% Confidence Intervals (Cl) were calculated by multivariable logistic regression models adjusted for age at interview, state, overweight/obese, ever smoked, spring or summer season, current occupational pesticides use. Bold shows ORs that are statistically significant at $p<0.05$.

${ }^{4}$ Mutually adjusted for correlated pesticides (see Supplemental Table 2).

The carbamate insecticide aldicarb was the only other insecticide associated with high ANA; although it has a high acute toxicity, its immune effects are not well-known (3941). The other carbamate insecticides, carbaryl and carbofuran, were not associated with elevated ANA. However, all but one of the participants with disease-specific autoantibodies had used carbofuran. High ANA was suggestively associated with the organophosphate insecticide diazinon, and we noted increased ORs for the two other phosphorothioates, chlorpyrifos, and coumaphos, though neither was statistically significant. These chemicals have documented immunotoxic effects (4245). Conversely, the phosphorodithioate insecticides fonofos and malathion were inversely associated with overall ANA, and the other phosphorodithioate insecticides also showed inverse, though not statistically significant, associations with overall ANA. There is some evidence of immunosuppression by malathion (46), while other studies (including in a MRL-lpr lupus mouse model) suggest that malathion may stimulate and accelerate the onset and intensity of the autoimmune response $(47,48)$. Immune effects of fonofos are not described in the literature, and our findings seem somewhat paradoxical; while inversely associated with overall ANA, fonofos was positively associated with disease-specific autoantibodies in those with moderate to high ANA compared with no ANA detected. The primary mechanism of action for organophosphate and carbamate insecticides is blocking acetylcholinesterase enzyme. Given cholinergic receptors on human lymphocytes, pesticides may influence the immune response through acetylchlolinergic pathways, though the direction of effects may depend on the activated pathway $(49,50)$. The phosphorodithioates require oxidative activation in vivo. However, it is unclear how this would differentially influence immune-related mechanisms of action compared with the other organophosphates and carbamates.

We also saw an association of high or moderate level ANA with the fumigant methyl bromide. Ethylene dibromide was also associated with disease-specific autoantibodies. Immunerelated mechanisms of these highly toxic chemicals are not well-described in the literature, although one study suggested a similar threshold for immune modulation and the level at which acute toxicity occurred $(51,52)$. Along with aldicarb and carbofuran, methyl bromide and ethylene dibromide are often used against nematodes. Many participants with elevated ANA and disease-specific autoantibodies used more than one of these chemicals, but we did not have sufficient sample size to examine them independently. Use of petroleum oil or distillates was also associated with high or moderate ANA. Petroleum oil is a plausible candidate for inducing systemic autoimmunity, given the model of pristane-induced lupus (53). Pristane is a byproduct of petroleum distillation and induces lupus-like autoantibodies and clinical disease in mice. Petroleum distillates in the past may also have included other contaminants such as benzene or xylene. Overall ANA prevalence was inversely associated with butylate, a thiocarbamate herbicide, linked to lymphohematopoetic cancers and NHL in the AHS (54), but immune effects are not described in the literature. Interestingly, past use of butylate and recent use of malathion were associated with shorter leukocyte telomere length, a potential marker of immune aging, in a different subsample of AHS participants (55). 
TABLE 4 | ANA associations with intensity-weighted lifetimes days of organochlorine use.

\begin{tabular}{|c|c|c|c|c|c|c|c|}
\hline \multirow{3}{*}{ Intensity weighted lifetime days ${ }^{2}$} & \multicolumn{4}{|c|}{ ANA Level ${ }^{1}$} & \multicolumn{3}{|c|}{ Adjusted OR $(95 \% \mathrm{Cl})^{3}$} \\
\hline & $\begin{array}{l}\text { Negative } \\
N=227\end{array}$ & $\begin{array}{l}1: 802+ \\
N=88\end{array}$ & $\begin{array}{c}1: 803 / 4+ \\
N=51\end{array}$ & $\begin{array}{c}1: 1603 / 4+ \\
N=40\end{array}$ & $\begin{array}{l}\text { Any ANA } \\
(\geq 1: 802+) \\
\text { vs. none }\end{array}$ & $\begin{array}{l}\text { Moderate-higher } \\
\begin{array}{c}(\geq 1: 803 / 4+) \\
\text { vs. none }\end{array}\end{array}$ & $\begin{array}{c}\text { Higher } \\
(\geq 1: 1603 / 4+) \\
\text { vs. none }\end{array}$ \\
\hline & \multicolumn{4}{|c|}{$N(\%)$} & & & \\
\hline \multicolumn{8}{|l|}{ Cyclodienes $^{4}$} \\
\hline None & $151(66)$ & $57(65)$ & 32 (63) & $20(50)$ & 1.0 (referent) & 1.0 (referent) & 1.0 (referent) \\
\hline Tertile 1 & $23(10)$ & $13(15)$ & $8(16)$ & $4(10)$ & $1.29(0.66,2.49)$ & $1.40(0.62,3.17)$ & $1.27(0.38,4.24)$ \\
\hline Tertile 2 & $29(13)$ & $10(11)$ & $4(8)$ & $6(14)$ & $0.76(0.38,1.51)$ & $0.84(0.36,1.99)$ & $1.14(0.38,3.42)$ \\
\hline Tertile 3 & $24(11)$ & $8(9)$ & $7(14)$ & $10(25)$ & $1.33(0.64,2.75)$ & $2.58(1.09,6.09)$ & $3.20(1.10,9.27)$ \\
\hline \multicolumn{8}{|l|}{ Other OC $^{3}$} \\
\hline None & $147(65)$ & $55(63)$ & $35(69)$ & $26(65)$ & 1.0 (referent) & 1.0 (referent) & 1.0 (referent) \\
\hline Tertile 1 & $22(10)$ & $13(15)$ & $9(18)$ & $3(8)$ & $1.23(0.63,2.41)$ & $1.14(0.50,2.60)$ & $0.62(0.16,2.40)$ \\
\hline Tertile 2 & $29(13)$ & $8(9)$ & $5(10)$ & $7(17)$ & $0.78(0.41,1.51)$ & $0.82(0.37,1.79)$ & $0.95(0.35,2.57)$ \\
\hline Tertile 3 & $29(13)$ & $12(14)$ & $2(4)$ & $4(10)$ & $0.58(0.28,1.23)$ & $0.24(0.08,0.72)$ & $0.26(0.07,1.03)$ \\
\hline
\end{tabular}

NA, not applicable due to fewer than five exposed cases.

${ }^{1}$ ANA Level shows four exclusive categories of ANA positivity based on highest reading observed.

${ }^{2}$ Limited to applicators who completed the take-home questionnaire with information on frequency and duration of use.

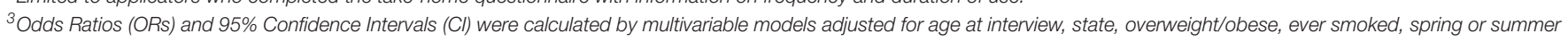
season, current occupational pesticides use. Bold shows ORs that are statistically significant at $p<0.05$.

${ }^{4}$ ORs for tertiles of cyclodienes (aldrin, chlordane, dieldrin, or heptachlor) and other organochlorines (OCs, DDT, lindane, or toxaphene), mutually adjusted.

Our results also suggest that seeking medical care due to pesticide exposure (i.e., seeing a doctor or being hospitalized due to pesticide exposure, or being diagnosed with pesticide poisoning) was associated with having moderate or high ANA. The reasons for seeking medical care for pesticide exposure included high pesticide exposure events (HPEE) and presumably pesticide-related symptoms, however we did not analyze ANA in relation to symptoms data. We also saw an elevated OR for overall ANA with HPEE in those who experienced an event but did not seek medical care (OR 1.37). Prior AHS research suggests those reporting high pesticide exposure events used pesticides for more days per year and had certain practices that might increase personal exposures, such as storing pesticides in the home or spraying pesticides with open cab windows, and that many do not seek medical care for HPEE and exposure-related symptoms (56). In our study, among ANA positive individuals, only 21 (3\% of the total) reported both HPEE and seeking medical care, while 39 (6\%) sought medical care without reporting HPEE, and 88 (13\%) reported only HPEE (not shown in tables). Thus, the actual exposures underlying our findings remain undetermined. The AHS collected data on specific pesticides involved in some high pesticide exposure events, but we had insufficient sample size to take advantage of these data.

Diverse and interrelated pathways lead to dysregulation of the immune response and development of autoimmunity. In healthy individuals, ANA may reflect increased exposure to self-antigens and dysregulation of various pathways, some of which are shared and others distinctive from patterns seen in autoimmune disease patients $(57,58)$. Pesticides may influence both the generation of autoimmunity and the strength of the immune response. Our study used the gold standard assay, which is sensitive to lower levels of ANA at the 1:40 dilution level while providing increased specificity at higher titers (e.g., 1:160). ANA are thought to arise as an immune response to nuclear antigens released from apoptotic cells. The interpretation of ANA detection at different thresholds for positivity varies by context: although detection at the 1:80 dilution of 3 or $4+$ intensity has recently been specified among the constellation of clinical criteria for systemic lupus erythematosus, higher levels may be seen in lupus and sometimes associated with other clinical autoimmune diseases (59). Interestingly, we only saw positive associations for moderate or higher-level ANA, while inverse associations were seen only with having any detectable ANA (including lower levels, at least $2+$ intensity at the 1:80 dilution).

A positive response to the HEp-2 ANA assay does not imply an association with clinical disease. The pattern of nuclear antibody staining is emerging as a key means to differentiate the origins and relevance of ANA in clinical and healthy populations, especially the dense fine speckled pattern and the associated anti-DFS70 antibody (60-62). Our analyses did not consider the fluorescence pattern, as the vast majority of ANA were identified as fine speckled, which at the time of the study was not differentiated from dense fine speckled and speckled. Antibodies to DFS70 may be a promising marker, as they appear to be more common in the general population and may even help to rule-out specific autoimmune diseases (60); had use of this marker been more common and validated at the time of the original testing, it would have been considered. We focused on specific disease-associated autoantibodies commonly examined in clinical assessments for SLE, but our results support further investigation of other types of antibodies as well, such as antihistone and chromatin, which have been linked with certain 
TABLE 5 | ENA and anti-dsDNA autoantibodies by lifetime pesticide use ${ }^{1}$.

\begin{tabular}{|c|c|c|c|c|c|c|c|}
\hline & \multicolumn{2}{|c|}{ ANA Negative $(N=386)$} & \multicolumn{2}{|c|}{ ENA/anti-dsDNA $(N=15)$} & \multicolumn{2}{|c|}{ Age-adjusted odds ratio $(95 \% \mathrm{Cl})^{2}$} & \multirow[b]{2}{*}{$p$-value } \\
\hline & $N$ & $\%$ & $N$ & $\%$ & & & \\
\hline \multicolumn{8}{|c|}{ ORGANOCHLORINE INSECTICIDES } \\
\hline \multicolumn{8}{|l|}{ Cyclodienes } \\
\hline Aldrin & 81 & 22 & 9 & 60 & 3.39 & $(0.98,11.7)$ & 0.054 \\
\hline Chlordane & 103 & 28 & 8 & 53 & 1.72 & $(0.55,5.36)$ & 0.350 \\
\hline Dieldrin & 31 & 8 & 5 & 33 & 3.29 & $(0.88,12.3)$ & 0.076 \\
\hline Heptachlor & 70 & 19 & 7 & 47 & 2.86 & $(0.80,10.2)$ & 0.106 \\
\hline Only one & 78 & 21 & 2 & 13 & 1.39 & $(0.21,9.08)$ & 0.729 \\
\hline 2 or more & 74 & 20 & 10 & 67 & 6.48 & $(1.45,29.0)$ & 0.015 \\
\hline \multicolumn{8}{|l|}{ Others } \\
\hline DDT & 87 & 23 & 7 & 47 & 1.06 & $(0.29,3.84)$ & 0.934 \\
\hline Lindane & 110 & 29 & 8 & 53 & 2.27 & $(0.77,6.71)$ & 0.140 \\
\hline Toxaphene & 57 & 15 & 3 & 21 & 0.76 & $(0.18,3.19)$ & 0.708 \\
\hline One & 103 & 27 & 2 & 13 & 0.45 & $(0.08,2.41)$ & 0.352 \\
\hline 2 or more & 65 & 17 & 7 & 47 & 1.74 & $(0.47,6.43)$ & 0.403 \\
\hline \multicolumn{8}{|c|}{ OTHER INSECTICIDES } \\
\hline Chlorpyrifos & 211 & 55 & 5 & 33 & 0.45 & $(0.14,1.39)$ & 0.166 \\
\hline Coumaphos & 39 & 10 & 1 & 7 & 0.57 & $(0.07,4.74)$ & 0.607 \\
\hline Diazinon & 112 & 29 & 6 & 40 & 1.20 & $(0.39,3.71)$ & 0.746 \\
\hline DDVP & 66 & 17 & 5 & 33 & 2.12 & $(0.64,7.01)$ & 0.218 \\
\hline Fonofos & 136 & 35 & 9 & 60 & 3.70 & $(1.01,13.5)$ & 0.048 \\
\hline Parathion & 53 & 14 & 3 & 20 & 0.88 & $(0.22,3.55)$ & 0.863 \\
\hline Malathion & 318 & 82 & 9 & 60 & 0.31 & $(0.10,0.95)$ & 0.041 \\
\hline Phorate & 158 & 41 & 9 & 60 & 2.63 & $(0.70,9.88)$ & 0.152 \\
\hline Terbufos & 212 & 55 & 10 & 67 & 3.32 & $(0.87,12.6)$ & 0.078 \\
\hline Carbofuran & 144 & 37 & 14 & 93 & 30.0 & $(3.59,251)$ & 0.002 \\
\hline Carbaryl & 204 & 53 & 10 & 67 & 1.41 & $(0.44,4.55)$ & 0.562 \\
\hline Aldicarb & 20 & 5 & 3 & 20 & 5.28 & $(0.95,29.5)$ & 0.058 \\
\hline Permethrin & 145 & 38 & 3 & 20 & 0.41 & $(0.11,1.56)$ & 0.190 \\
\hline \multicolumn{8}{|l|}{ HERBICIDES } \\
\hline $2,4-D$ & 338 & 88 & 14 & 93 & 1.77 & $(0.21,15.2)$ & 0.604 \\
\hline $2,4,5-\mathrm{T}$ & 102 & 26 & 7 & 47 & 1.47 & $(0.47,4.63)$ & 0.512 \\
\hline Atrazine & 331 & 86 & 14 & 93 & 2.44 & $(0.28,21.4)$ & 0.421 \\
\hline Cyanazine & 207 & 54 & 12 & 80 & 5.34 & $(1.12,25.4)$ & 0.035 \\
\hline Metribuzin & 209 & 54 & 9 & 60 & 1.21 & $(0.37,3.89)$ & 0.754 \\
\hline Chlorimuron ethyl & 150 & 39 & 7 & 47 & 1.23 & $(0.41,3.67)$ & 0.713 \\
\hline Metolachlor & 221 & 57 & 9 & 60 & 1.20 & $(0.39,3.66)$ & 0.745 \\
\hline Alachlor & 247 & 64 & 10 & 67 & 1.47 & $(0.44,4.96)$ & 0.532 \\
\hline EPTC & 82 & 21 & 5 & 33 & 2.42 & $(0.73,8.06)$ & 0.149 \\
\hline Trifluralin & 208 & 54 & 9 & 60 & 1.09 & $(0.35,3.42)$ & 0.882 \\
\hline Butylate & 190 & 49 & 9 & 60 & 1.77 & $(0.56,5.60)$ & 0.330 \\
\hline Imazethapyr & 178 & 46 & 9 & 60 & 3.02 & $(0.79,11.6)$ & 0.107 \\
\hline Dicamba & 268 & 69 & 11 & 73 & 1.78 & $(0.37,8.55)$ & 0.474 \\
\hline Paraquat & 87 & 23 & 4 & 27 & 0.95 & $(0.27,3.31)$ & 0.941 \\
\hline Glyphosate & 353 & 92 & 12 & 80 & 0.41 & $(0.10,1.65)$ & 0.209 \\
\hline Pendimethalin & 193 & 50 & 9 & 60 & 2.02 & $(0.66,6.24)$ & 0.220 \\
\hline Petroleum_oil & 204 & 53 & 10 & 67 & 1.82 & $(0.56,5.90)$ & 0.321 \\
\hline \multicolumn{8}{|c|}{ FUNGICIDES, FUMIGANTS } \\
\hline Benomyl & 26 & 7 & 3 & 20 & 1.92 & $(0.42,8.73)$ & 0.397 \\
\hline Captan & 53 & 14 & 3 & 20 & 1.61 & $(0.42,6.18)$ & 0.489 \\
\hline
\end{tabular}




\begin{tabular}{|c|c|c|c|c|c|c|c|}
\hline & \multicolumn{2}{|c|}{ ANA Negative $(N=386)$} & \multicolumn{2}{|c|}{ ENA/anti-dsDNA $(N=15)$} & \multicolumn{2}{|c|}{ Age-adjusted odds ratio $(95 \% \mathrm{CI})^{2}$} & $p$-value \\
\hline Methyl bromide & 25 & 6 & 3 & 20 & 16.6 & $(0.92,299)$ & 0.057 \\
\hline Aluminum Phosphide & 23 & 6 & 2 & 13 & 2.20 & $(0.44,11.0)$ & 0.337 \\
\hline Ethylene Dibromide & 13 & 3 & 3 & 20 & 5.07 & $(1.10,23.4)$ & 0.038 \\
\hline
\end{tabular}

ENA (Extractable Nuclear Antigens) measured on those ANA read as 3 or 4+ at 1:80 dilution; ANA Negative = none detected at 1:80 dilution.

${ }^{1}$ Reported ever use at AHS enrollment (1993-1997) based on list of 50 specific pesticides, with updated use throughout follow-up and BEEA enrollment.

${ }^{2}$ Odds Ratios (ORs) and 95\% Confidence Intervals (Cl) were calculated by multivariable logistic regression models adjusted for age at interview.

drug- and xenobiotic exposures and may help to identify the underlying role of specific exposures (63-66).

Half of the ANA-positive individuals in our study sample were positive only at the lowest-level (2+ at a 1:80 dilution); this threshold was used to enable comparisons with studies using a lower dilution (i.e., 1:40). The implications of having lower-level ANA are not well-understood. Most research on autoimmunity in the absence of autoimmune diseases has been based on cross-sectional and clinical samples; however, a few longitudinal studies showing that individuals with low level ANA are more likely to revert to seronegative status over time compared to those at lower titers $(22,62,67)$. Notably, in a sample of rural residents and farmers, Semchuk observed that ANA prevalence at higher titers $(3+$ or $4+$ at $1: 80$ and $1: 160)$ was similar in the summer and winter, with similar rates of seroconversion and reversion across the seasons (16). On the other hand, lower level ANA (at the at 1:40 dilution, but not higher) were elevated in summer, supporting the idea that changing exposures by season may account for transient expression of ANA in some individuals. Although we adjusted for season in our statistical models, we saw no strong or consistent differences in ANA frequency for participants sampled at different times of year. Smoking history and BMI at the time of sampling were non-significantly associated with ANA and were included in our multivariable models along with other covariates as they generally increased the precision of observed associations. The causal relationship of specific pesticides with BMI is unknown; however, adjusting for BMI did not appear to explain any of the observed pesticide associations. Odds ratios approximate the relative risk for rare outcomes $(<10 \%)$, for example with high ANA and ENA, but overestimate the relative risk for more common outcomes (i.e., overall ANA or high/moderate ANA). Our estimated ORs, therefore, may most accurately reflect the relative risks for high ANA. On the other hand, small numbers may inflate the OR and confidence limits, for example, in the analyses of uncommon pesticides and diseasespecific autoantibodies.

We excluded prevalent cases of autoimmune diseases (e.g., rheumatoid arthritis and lupus) to reduce potential recall or reporting bias, or changes in exposures due to health conditions; in follow-up, some participants reported incident autoimmune diseases, which were associated with ANA as expected (Supplemental Table 1). Overall ANA (i.e., including low level ANA) was also associated with antiTPO autoantibodies. Autoimmune thyroid diseases occur more often in those with systemic autoimmune diseases (68), and anti-TPO autoantibodies have been previously associated with ANA in healthy controls (57). Prevalence of antiCCP autoantibodies, specific for rheumatoid arthritis, was not associated with ANA in our sample, and levels were similar to the general population (69-71), despite evidence that rheumatoid arthritis may be associated with agricultural work and pesticide use in the AHS and other studies (1-9). Sensitivity analyses showed no substantial changes after excluding possible new cases of autoimmune diseases and those specific autoantibodies (i.e., anti-CCP, anti-TPO, and disease specific ENA and anti-dsDNA autoantibodies) (not shown).

The BEEA study provides an opportunity to investigate the long-term health effects of pesticides and other agricultural exposures on autoimmunity. The study sample is representative of men who were actively farming at AHS enrollment in the mid-1990s, most of whom did not have a diagnosis of RA or other autoimmune diseases. Women in the AHS, mostly spouses of the licensed applicators, were not included in the BEEA sample. Spouses reported less pesticide use than the applicators, but potential associations of pesticides with ANA in spouses may be relevant given the higher prevalence of ANA in women generally. Farmers are a unique population, with diverse exposures to agricultural pesticides and other physical or chemical factors, so results may not be generalizable to the general population. Further research is warranted to investigate ANA in relation to other agricultural factors, for example to solvents and fertilizers, recently associated with rheumatoid arthritis in the AHS (72). Our study addresses several limitations of prior studies on pesticides and ANA, with data on lifetime exposure to over 40 specific agricultural pesticides. However, despite having a larger sample than most studies, we had low statistical power to examine associations with uncommon pesticides and disease-specific autoantibodies, and for testing exposure-response gradients. Non-differential exposure misclassification is a possibility due to errors in recall of past exposures. Evaluation of self-reported data in the AHS has established the reliability of recall for specific pesticides; further, an intensity-weighting algorithm developed for the study (integrating across multiple determinants of exposure 
intensity) has shown good correlation with measurement data in an exposure sub-study, and may reduce the potential for non-differential misclassification to bias results toward the null in analyses of dose-response $(24,73,74)$.

Our analyses are based on prospectively collected exposure data, but temporal ambiguity relative to ANA incidence is inherent to our study design focused on lifetime exposures. We cannot know whether exposures occurred prior to or after the development of ANA, or whether ANA appeared in the past and became non-detectable at the time they were measured. While the natural history of ANA in the general population is not well-understood, ANA prevalence typically increases with age, suggesting increasing incidence of ANA over time. Presumably, pesticides may influence two processes that contribute to the observed ANA at a single time point: (1) the breach of immune tolerance and initial production of autoantibodies, and (2) external factors impacting the production of measurable levels at the time of sampling. Further research is needed to investigate the associations of ANA with contemporary use of specific pesticides and the time since last use. Autoantibodies can precede the development of autoimmune diseases for a decade or longer (75), so other factors are likely to contribute to the development of pathology and disease.

Altogether our findings provide evidence that past pesticide use may influence the development of autoimmunity in middle age and older farmers, consistent with prior findings of elevated ANA with some organochlorine insecticides. The presence of disease-specific autoantibodies was also related to certain organochlorines, supporting the need to further explore these persistent pesticides as potential causal agents in development of autoimmune diseases. Future research should focus on the role of recent exposure and the evaluation of less common pesticides in larger studies or in targeted populations with greater use of these chemicals.

\section{DATA AVAILABILITY}

Due to ethical restrictions imposed in the interest of protecting participant confidentiality, the datasets for this study are available upon request to interested, qualified researchers. Requests to access the datasets should be directed to JH (hofmannjn@mail.nih.gov).

\section{REFERENCES}

1. Gold LS, Ward MH, Dosemeci M, De Roos AJ. Systemic autoimmune disease mortality and occupational exposures. Arthritis Rheum. (2007) 56:3189-201. doi: 10.1002/art.22880

2. Lundberg I, Alfredsson L, Plato N, Sverdrup B, Klareskog L, Kleinau S. Occupation, occupational exposure to chemicals and rheumatological disease. A register based cohort study. Scand J Rheumatol. (1994) 23:305-10. doi: 10.3109/03009749409099278

3. Milham S Jr. Using multiple cause of death coding in occupational mortality studies. Am J Ind Med. (1988) 14:341-4. doi: 10.1002/ajim.47001 40311

\section{ETHICS STATEMENT}

The study was approved by Institutional Review Boards at the National Cancer Institute and other participating institutions, and all participants provided written informed consent.

\section{AUTHOR CONTRIBUTIONS}

$\mathrm{CP}$ conceived of the research question, obtained funding for assays, performed analyses, evaluated results, and wrote the manuscript. AS assisted with planning analyses, evaluated results, and contributed to the manuscript. SB, MW, and CL assisted with planning analyses, evaluating results, and editing the manuscript. $\mathrm{JH}, \mathrm{DS}, \mathrm{MA}, \mathrm{CD}$, and LB obtained funding and generated data for the AHS and BEEA sub-cohort, assisted with planning analyses, evaluated results, and edited the manuscript.

\section{FUNDING}

This work was supported by the Intramural Research Program of the NIH, National Institute of Environmental Health Sciences (Z01-ES049030) and National Cancer Institute (Z01-CP010119).

\section{ACKNOWLEDGMENTS}

The authors thank Stuart Long, Westat, for programming support, and Fred Miller and Srishti Shrestha for helpful reviews of manuscript drafts. We would also like to thank Amy Miller, Kate Torres, Sandor Balogh, Marsha Dunn, and other staff at Westat, Inc. (Rockville, Maryland) and Charles Lynch, Debra Lande, Debra Podaril, and Jennifer Hamilton (University of Iowa) for study coordination, data management, and field research efforts. We also thank Kevin Deane (University of Colorado) for assay support, as well as Anne Taylor and Peter Hui (Information Management Services, Rockville, Maryland) for data management and analytic support. The authors gratefully acknowledge the ongoing participation of the Agricultural Health Study participants that made this work possible.

\section{SUPPLEMENTARY MATERIAL}

The Supplementary Material for this article can be found online at: https://www.frontiersin.org/articles/10.3389/fimmu. 2019.01476/full\#supplementary-material

4. Khuder SA, Peshimam AZ, Agraharam S. Environmental risk factors for rheumatoid arthritis. Rev Environ Health. (2002) 17:307-15. doi: 10.1515/REVEH.2002.17.4.307

5. Li X, Sundquist J, Sundquist K. Socioeconomic and occupational risk factors for rheumatoid arthritis: a nationwide study based on hospitalizations in Sweden. J Rheumatol. (2008) 35:986-91.

6. Lee E, Burnett CA, Lalich N, Cameron LL, Sestito JP. Proportionate mortality of crop and livestock farmers in the United States, 1984-1993. Am J Ind Med. (2002) 42:410-20. doi: 10.1002/ajim.10131

7. Olsson AR, Skogh T, Wingren G. Occupational determinants for rheumatoid arthritis. Scand J Work Environ Health. (2000) 26:243-9. doi: $10.5271 /$ sjweh.538 
8. Meyer A, Sandler DP, Beane Freeman LE, Hofmann JN, Parks CG. Pesticide exposure and risk of rheumatoid arthritis among licensed male pesticide applicators in the Agricultural Health Study. Environ Health Perspect. (2017) 125:077010. doi: 10.1289/EHP1013

9. Parks CG, Hoppin JA, De Roos AJ, Costenbader KH, Alavanja MC, Sandler DP. Rheumatoid arthritis in Agricultural Health Study Spouses: associations with pesticides and other farm exposures. Environ Health Perspect. (2016) 124:1728-34. doi: 10.1289/EHP129

10. Satoh M, Chan EK, Ho LA, Rose KM, Parks CG, Cohn RD, et al. Prevalence and sociodemographic correlates of antinuclear antibodies in the United States. Arthritis Rheum. (2012) 64:2319-27. doi: 10.1002/art.34380

11. Tan EM, Feltkamp TE, Smolen JS, Butcher B, Dawkins R, Fritzler MJ, et al. Range of antinuclear antibodies in "healthy" individuals. Arthritis Rheum. (1997) 40:1601-11. doi: 10.1002/art.1780400909

12. Munroe ME, Young KA, Kamen DL, Guthridge JM, Niewold TB, Costenbader $\mathrm{KH}$, et al. Discerning risk of disease transition in relatives of systemic lupus erythematosus patients utilizing soluble mediators and clinical features. Arthritis Rheumatol. (2017) 69:630-42. doi: 10.1002/art.40004

13. Elnady BM, Kamal NM, Shaker RH, Soliman AF, Hasan WA, Alghamdi HA, et al. Prevalence and clinical significance of nonorgan specific antibodies in patients with autoimmune thyroiditis as predictor markers for rheumatic diseases. Medicine. (2016) 95:e4336. doi: 10.1097/MD.0000000000004336

14. Corsini E, Sokooti M, Galli CL, Moretto A, Colosio C. Pesticide induced immunotoxicity in humans: a comprehensive review of the existing evidence. Toxicology. (2013) 307:123-35. doi: 10.1016/j.tox.2012.10.009

15. Rosenberg AM, Semchuk KM, McDuffie HH, Ledingham DL, Cordeiro DM, Cessna AJ, et al. Prevalence of antinuclear antibodies in a rural population. $J$ Toxicol Environ Health A. (1999) 57:225-36. doi: 10.1080/009841099157674

16. Semchuk KM, Rosenberg AM, McDuffie HH, Cessna AJ, Pahwa P, Irvine DG. Antinuclear antibodies and bromoxynil exposure in a rural sample. J Toxicol Environ Health A. (2007) 70:638-57. doi: 10.1080/15287390600974593

17. Dinse GE, Jusko TA, Whitt IZ, Co CA, Parks CG, Satoh M, et al. Associations between selected xenobiotics and antinuclear antibodies in the national health and nutrition examination survey, 1999-2004. Environ Health Perspect. (2016) 124:426-36. doi: 10.1289/ehp.1409345

18. McConnachie PR, Zahalsky AC. Immune alterations in humans exposed to the termiticide technical chlordane. Arch Environ Health. (1992) 47:295-301. doi: 10.1080/00039896.1992.9938365

19. Cooper GS, Martin SA, Longnecker MP, Sandler DP, Germolec DR. Associations between plasma DDE levels and immunologic measures in African-American farmers in North Carolina. Environ Health Perspect. (2004) 112:1080-4. doi: 10.1289/ehp.6892

20. Hofmann JN, Beane Freeman LE, Lynch CF, Andreotti G, Thomas KW, Sandler DP, et al. The biomarkers of exposure and effect in agriculture (BEEA) study: rationale, design, methods, and participant characteristics. J Toxicol Environ Health A. (2015) 78:1338-47. doi: 10.1080/15287394.2015.1091414

21. Alavanja MC, Sandler DP, McMaster SB, Zahm SH, McDonnell CJ, Lynch CF, et al. The Agricultural Health Study. Environ Health Perspect. (1996) 104:362-9. doi: 10.1289/ehp.96104362

22. Xavier RM, Yamauchi Y, Nakamura M, Tanigawa Y, Ishikura H, Tsunematsu $\mathrm{T}$, et al. Antinuclear antibodies in healthy aging people: a prospective study. Mech Ageing Dev. (1995) 78:145-54. doi: 10.1016/0047-6374(94)01532-Q

23. Guo YP, Wang CG, Liu X, Huang YQ, Guo DL, Jing XZ, et al. The prevalence of antinuclear antibodies in the general population of china: a cross-sectional study. Curr Ther Res Clin Exp. (2014) 76:116-9. doi: 10.1016/j.curtheres.2014.06.004

24. Coble J, Thomas KW, Hines CJ, Hoppin JA, Dosemeci M, Curwin B, et al. An updated algorithm for estimation of pesticide exposure intensity in the agricultural health study. Int J Environ Res Public Health. (2011) 8:4608-22. doi: 10.3390/ijerph8124608

25. Alavanja MC, Sandler DP, McDonnell CJ, Mage DT, Kross BC, Rowland AS, et al. Characteristics of persons who self-reported a high pesticide exposure event in the Agricultural Health Study. Environ Res. (1999) 80:180-6. doi: 10.1006/enrs.1998.3887

26. Kuller LH, Mackey RH, Walitt BT, Deane KD, Holers VM, Robinson WH, et al. Determinants of mortality among postmenopausal women in the women's health initiative who report rheumatoid arthritis. Arthritis Rheumatol. (2014) 66:497-507. doi: 10.1002/art.38268
27. Jorgensen KT, Wiik A, Pedersen M, Hedegaard CJ, Vestergaard BF, Gislefoss $\mathrm{RE}$, et al. Cytokines, autoantibodies and viral antibodies in premorbid and postdiagnostic sera from patients with rheumatoid arthritis: case-control study nested in a cohort of Norwegian blood donors. Ann Rheum Dis. (2008) 67:860-6. doi: 10.1136/ard.2007.073825

28. Lerro CC, Beane Freeman LE, DellaValle CT, Kibriya MG, AschebrookKilfoy B, Jasmine F, et al. Occupational pesticide exposure and subclinical hypothyroidism among male pesticide applicators. Occup Environ Med. (2018) 75:79-89. doi: 10.1136/oemed-2017-104431

29. Sobel ES, Gianini J, Butfiloski EJ, Croker BP, Schiffenbauer J, Roberts SM. Acceleration of autoimmunity by organochlorine pesticides in (NZB x NZW)F1 mice. Environ Health Perspect. (2005) 113:323-8. doi: 10.1289/ehp.7347

30. Coats JR. Mechanisms of toxic action and structure-activity relationships for organochlorine and synthetic pyrethroid insecticides. Environ Health Perspect. (1990) 87:255-62. doi: 10.1289/ehp.9087255

31. Kim JK, Kim YS, Lee HM, Jin HS, Neupane C, Kim S, et al. GABAergic signaling linked to autophagy enhances host protection against intracellular bacterial infections. Nat Commun. (2018) 9:4184. doi: 10.1038/s41467-018-06487-5

32. Wu CY, Gagnon DA, Sardin JS, Barot U, Telenson A, Arratia PE, et al. Enhancing GABAergic transmission improves locomotion in a caenorhabditis elegans model of spinal muscular atrophy. eNeuro. (2018) 5 . doi: 10.1523/ENEURO.0289-18.2018. Available online at: http://www.eneuro. org/content/5/6/ENEURO.0289-18.2018.long

33. Holsapple MP. Autoimmunity by pesticides: a critical review of the state of the science. Toxicol Lett. (2002) 127:101-9. doi: 10.1016/S0378-4274(01)00489-1

34. Loose LD, Silkworth JB, Charbonneau T, Blumenstock F. Environmental chemical-induced macrophage dysfunction. Environ Health Perspect. (1981) 39:79-92. doi: 10.2307/3429282

35. Hugo P, Bernier J, Krzystyniak K, Potworowski EF, Fournier M. Abrogation of graft-versus-host reaction by dieldrin in mice. Toxicol Lett. (1988) 41:11-22. doi: 10.1016/0378-4274(88)90003-3

36. Fournier M, Chevalier G, Nadeau D, Trottier B, Krzystyniak K. Viruspesticide interactions with murine cellular immunity after sublethal exposure to dieldrin and aminocarb. J Toxicol Environ Health. (1988) 25:103-18. doi: 10.1080/15287398809531192

37. Briz V, Molina-Molina JM, Sanchez-Redondo S, Fernandez MF, Grimalt JO, Olea $\mathrm{N}$, et al. Differential estrogenic effects of the persistent organochlorine pesticides dieldrin, endosulfan, and lindane in primary neuronal cultures. Toxicol Sci. (2011) 120:413-27. doi: 10.1093/toxsci/ kfr019

38. Coumoul X, Diry M, Barouki R. PXR-dependent induction of human CYP3A4 gene expression by organochlorine pesticides. Biochem Pharmacol. (2002) 64:1513-9. doi: 10.1016/S0006-2952(02)01298-4

39. Thomas PT, Ratajczak HV. Assessment of carbamate pesticide immunotoxicity. Toxicol Ind Health. (1988) 4:381-90. doi: $10.1177 / 074823378800400310$

40. Hajoui O, Flipo D, Mansour S, Fournier M, Krzystyniak K. Immunotoxicity of subchronic versus chronic exposure to aldicarb in mice. Int $J$ Immunopharmacol. (1992) 14:1203-11. doi: 10.1016/0192-0561(92)90056-Q

41. Thomas P, Ratajczak H, Demetral D, Hagen K, Baron R. Aldicarb immunotoxicity: functional analysis of cell-mediated immunity and quantitation of lymphocyte subpopulations. Fundam Appl Toxicol. (1990) 15:221-30. doi: 10.1093/toxsci/15.2.221

42. Duramad P, Tager IB, Leikauf J, Eskenazi B, Holland NT. Expression of Th1/Th2 cytokines in human blood after in vitro treatment with chlorpyrifos, and its metabolites, in combination with endotoxin LPS and allergen Der p1. J Appl Toxicol. (2006) 26:458-65. doi: 10.1002/jat.1162

43. Thrasher JD, Heuser G, Broughton A. Immunological abnormalities in humans chronically exposed to chlorpyrifos. Arch Environ Health. (2002) 57:181-7. doi: 10.1080/00039890209602934

44. Alluwaimi AM, Hussein Y. Diazinon immunotoxicity in mice: modulation of cytokines level and their gene expression. Toxicology. (2007) 236:123-31. doi: 10.1016/j.tox.2007.04.004

45. Neishabouri EZ, Hassan ZM, Azizi E, Ostad SN. Evaluation of immunotoxicity induced by diazinon in C57bl/6 mice. Toxicology. (2004) 196:173-9. doi: 10.1016/j.tox.2003.08.012 
46. Banerjee BD, Pasha ST, Hussain QZ, Koner BC, and Ray A, A comparative evaluation of immunotoxicity of malathion after subchronic exposure in experimental animals. Indian J Exp Biol. (1998) 36:273-82.

47. Johnson VJ, Rosenberg AM, Lee K, Blakley BR. Increased T-lymphocyte dependent antibody production in female SJL/J mice following exposure to commercial grade malathion. Toxicology. (2002) 170:119-29. doi: 10.1016/S0300-483X(01)00515-7

48. Rodgers KE. Effects of oral administration of malathion on the course of disease in MRL-lpr mice. J Autoimmun. (1997) 10:367-73. doi: 10.1006/jaut.1997.0145

49. Fujii T, Mashimo M, Moriwaki Y, Misawa H, Ono S, Horiguchi K, et al. Expression and function of the cholinergic system in immune cells. Front Immunol. (2017) 8:1085. doi: 10.3389/fimmu.2017.01085

50. Bosmans G, Shimizu Bassi G, Florens M, Gonzalez-Dominguez E, Matteoli G, Boeckxstaens GE. Cholinergic modulation of type 2 immune responses. Front Immunol. (2017) 8:1873. doi: 10.3389/fimmu.2017.01873

51. Bulathsinghala AT, Shaw IC. The toxic chemistry of methyl bromide. Hum Exp Toxicol. (2014) 33:81-91. doi: 10.1177/0960327113493299

52. Ratajczak HV, Aranyi C, Bradof JN, Barbera P, Fugmann R, Fenters JD, et al. Ethylene dibromide: evidence of systemic and immunologic toxicity without impairment of in vivo host defenses. In Vivo. (1994) 8:879-84.

53. Freitas EC, de Oliveira MS, Monticielo OA. Pristane-induced lupus: considerations on this experimental model. Clin Rheumatol. (2017) 36:240314. doi: 10.1007/s10067-017-3811-6

54. Lynch SM, Mahajan R, Beane Freeman LE, Hoppin JA, Alavanja MC. Cancer incidence among pesticide applicators exposed to butylate in the Agricultural Health Study (AHS). Environ Res. (2009) 109:860-8. doi: 10.1016/j.envres.2009.06.006

55. Andreotti G, Hoppin JA, Hou L, Koutros S, Gadalla SM, Savage SA, et al. Pesticide use and relative leukocyte telomere length in the agricultural health study. PLoS ONE. (2015) 10:e0133382. doi: 10.1371/journal.pone.0133382

56. Payne K, Andreotti G, Bell E, Blair A, Coble J, Alavanja M. Determinants of high pesticide exposure events in the agricultural health cohort study from enrollment (1993-1997) through phase II (1999-2003). J Agric Saf Health. (2012) 18:167-79. doi: 10.13031/2013.41955

57. Li QZ, Karp DR, Quan J, Branch VK, Zhou J, Lian Y, et al. Risk factors for ANA positivity in healthy persons. Arthritis Res Ther. (2011) 13:R38. doi: 10.1186/ar3271

58. Slight-Webb S, Lu R, Ritterhouse LL, Munroe ME, Maecker HT, Fathman $\mathrm{CG}$, et al. Autoantibody-positive healthy individuals display unique immune profiles that may regulate autoimmunity. Arthritis Rheumatol. (2016) 68:2492-502. doi: 10.1002/art.39706

59. Leuchten N, Hoyer A, Brinks R, Schoels M, Schneider M, Smolen J, et al. Performance of antinuclear antibodies for classifying systemic lupus erythematosus: a systematic literature review and meta-regression of diagnostic data. Arthritis Care Res. (2018) 70:428-38. doi: 10.1002/acr.23292

60. Conrad K, Rober N, Andrade LE, Mahler M. The clinical relevance of Anti-DFS70 autoantibodies. Clin Rev Allergy Immunol. (2017) 52:202-16. doi: 10.1007/s12016-016-8564-5

61. Mahler M, Andrade LE, Casiano CA, Malyavantham K, Fritzler MJ. Implications for redefining the dense fine speckled and related indirect immunofluorescence patterns. Expert Rev Clin Immunol. (2019) 15:447-8. doi: 10.1080/1744666X.2019.1596802

62. Mariz HA, Sato EI, Barbosa SH, Rodrigues SH, Dellavance A, Andrade LE. Pattern on the antinuclear antibody-HEp-2 test is a critical parameter for discriminating antinuclear antibody-positive healthy individuals and patients with autoimmune rheumatic diseases. Arthritis Rheum. (2011) 63:191-200. doi: 10.1002/art.30084

63. Pollard KM, Lee DK, Casiano CA, Bluthner M, Johnston MM, Tan EM. The autoimmunity-inducing xenobiotic mercury interacts with the autoantigen fibrillarin and modifies its molecular and antigenic properties. I Immunol. (1997) 158:3521-8.
64. Pollard KM, Pearson DL, Hultman P, Deane TN, Lindh U, Kono DH. Xenobiotic acceleration of idiopathic systemic autoimmunity in lupus-prone bxsb mice. Environ Health Perspect. (2001) 109:27-33. doi: 10.1289/ehp.0110927

65. Pfau JC, Barbour C, Black B, Serve KM, Fritzler MJ. Analysis of autoantibody profiles in two asbestiform fiber exposure cohorts. $J$ Toxicol Environ Health A. (2018) 81:1015-27. doi: 10.1080/15287394.2018. 1512432

66. Erdei E, Shuey C, Pacheco B, Cajero M, Lewis J, Rubin RL. Elevated autoimmunity in residents living near abandoned uranium mine sites on the Navajo Nation. J Autoimmun. (2019) 99:15-23. doi: 10.1016/j.jaut.2019. 01.006

67. Hayashi N, Koshiba M, Nishimura K, Sugiyama D, Nakamura T, Morinobu $S$, et al. Prevalence of disease-specific antinuclear antibodies in general population: estimates from annual physical examinations of residents of a small town over a 5-year period. Mod Rheumatol. (2008) 18:153-60. doi: 10.1007/s10165-008-0028-1

68. Cooper GS, Bynum ML, Somers EC. Recent insights in the epidemiology of autoimmune diseases: improved prevalence estimates and understanding of clustering of diseases. J Autoimmun. (2009) 33:197-207. doi: 10.1016/j.jaut.2009.09.008

69. Kakumanu P, Yamagata H, Sobel ES, Reeves WH, Chan EK, Satoh M. Patients with pulmonary tuberculosis are frequently positive for anticyclic citrullinated peptide antibodies, but their sera also react with unmodified arginine-containing peptide. Arthritis Rheum. (2008) 58:1576-81. doi: 10.1002/art.23514

70. Avouac J, Gossec L, Dougados M. Diagnostic and predictive value of anti-cyclic citrullinated protein antibodies in rheumatoid arthritis: a systematic literature review. Ann Rheum Dis. (2006) 65:845-51. doi: 10.1136/ard.2006.051391

71. Fischer A, Solomon JJ, du Bois RM, Deane KD, Olson AL, FernandezPerez ER, et al. Lung disease with anti-CCP antibodies but not rheumatoid arthritis or connective tissue disease. Respir Med. (2012) 106:1040-7. doi: 10.1016/j.rmed.2012.03.006

72. Parks CG, Meyer A, Beane Freeman LE, Hofmann JN, Sandler DP. Farming tasks and the development of rheumatoid arthritis in the agricultural health study. Occup Environ Med. (2019) 76:243-9. doi: 10.1136/oemed-2018-105361

73. Blair A, Tarone R, Sandler D, Lynch CF, Rowland A, Wintersteen W, et al. Reliability of reporting on life-style and agricultural factors by a sample of participants in the Agricultural Health Study from Iowa. Epidemiology. (2002) 13:94-9. doi: 10.1097/00001648-200201000-00015

74. Blair A, Thomas K, Coble J, Sandler DP, Hines CJ, Lynch CF, et al. Impact of pesticide exposure misclassification on estimates of relative risks in the Agricultural Health Study. Occup Environ Med. (2011) 68:537-41. doi: 10.1136/oem.2010.059469

75. Ma WT, Chang C, Gershwin ME, Lian ZX. Development of autoantibodies precedes clinical manifestations of autoimmune diseases: a comprehensive review. J Autoimmun. (2017) 83:95-112. doi: 10.1016/j.jaut.2017. 07.003

Conflict of Interest Statement: The authors declare that the research was conducted in the absence of any commercial or financial relationships that could be construed as a potential conflict of interest.

Copyright (C) 2019 Parks, Santos, Lerro, DellaValle, Ward, Alavanja, Berndt, Beane Freeman, Sandler and Hofmann. This is an open-access article distributed under the terms of the Creative Commons Attribution License (CC BY). The use, distribution or reproduction in other forums is permitted, provided the original author(s) and the copyright owner(s) are credited and that the original publication in this journal is cited, in accordance with accepted academic practice. No use, distribution or reproduction is permitted which does not comply with these terms. 